\title{
RAZÕES HISTÓRICAS DAS FORMULAÇÕES DE JOHN DEWEY SOBRE DEMOCRACIA E EDUCAÇÃO ESCOLAR
}

\author{
HISTORICAL REASONS OF DEWEY'S FORMULATIONS ABOUT DEMOCRACY \\ AND SCHOOL EDUCATION
}

\section{RAZONES HISTORICAS DE LAS FORMULACIONES DE JOHN DEWEY SOBRE DEMOCRACIA Y EDUCACIÓN ESCOLAR}

Karine Biasotto

Mestre em Educação (UNIOESTE/PR) e professora da Rede Pública de Ensino do Estado do Paraná. kabiasotto@gmail.com

Maria Inalva Galter

Professora Doutora da Universidade Estadual do Oeste do Paraná (UNIOESTE/PR). mgalter@hotmail.com

\begin{abstract}
RESUMO: O artigo examina a proposta educacional de John Dewey (1859-1952) no contexto histórico estadunidense no transcorrer das décadas finais do século XIX e primeira metade do século XX, ressaltando o seu entendimento sobre a democracia e a educação escolar numa sociedade complexa. Considera que as formulações do autor respondem às demandas contraditórias da sociedade da época. O grande desenvolvimento da indústria, da ciência, da tecnologia e da vida urbana favorecia a confiança no bem-estar humano numa sociedade em processo de mudança e em franco crescimento. Não obstante, o acirramento de conflitos culturais, raciais, étnicos e classistas colocava na ordem do dia o debate entre diferentes propostas de regulação das práticas individuais e coletivas. Diante desse contexto, o autor, postulou a via democrática de organização social, defendendo a escola como lócus singular de experiências educativas compartidas que devia primar pelo desenvolvimento inteligente do indivíduo de modo a favorecer o uso pleno de todas as suas capacidades. Enfim, a formação escolar do indivíduo era condição para a garantia do seu próprio bem-estar e, por conseguinte para o interesse público recíproco dos homens.
\end{abstract}

PALAVRAS-CHAVE: Estados Unidos. John Dewey. Democracia. Educação escolar.

ABSTRACT: The article examines John Dewey's educational proposal in the historical north-american context during the final decades of the XIX century and first half of XX century, presenting his understanding about democracy and school education in a complex society. It considers that the author's formulations are answers to the contradictory demands of society. The huge development of industry, science, technology and urban life favored confidence in human welfare in a society undergoing a process of change and growth. Notwithstanding, cultural, racial, ethnic and classist conflicts put different proposals about regulations of individual and collective practicesals on the agenda. In light of this context, the author postulated democracy as a social organization, defending school as a singular lócus of shared educative experiences, that should focus on intelligent development of the individual in such a way as to favor the use of all capacities. Finally, the schooling of each individual was the condition to ensure his own well being and consequently, for reciprocal public interest of human beings..

KEYWORDS: United States. John Dewey. Democracy. School education.

RESUMEN: El artículo examina la propuesta educacional de John Dewey (1859-1952) en el contexto histórico de los Estados Unidos en el curso de las décadas finales del siglo XIX y la primera mitad del siglo XX, con relieve a su comprensión sobre la democracia y la educación escolar en una sociedad compleja. Se considera que las formulaciones del autor responden a las exigencias contradictorias de la sociedad del momento. El gran desarrollo de la industria, la ciencia, la tecnología y la vida urbana fomenta la confianza en el bienestar humano en una sociedad que estaba cambiando y creciendo rápidamente. Sin embargo, la intensificación de los conflictos culturales, raciales, étnicos y de clase puso en evidencia el debate entre diferentes propuestas de regulación de las prácticas individuales y colectivas. En este contexto, el autor postuló la forma democrática de organización social, defendiendo la escuela como un lócus singular de experiencias educativas compartidas que se debía primar por el desarrollo inteligente de la persona con el fin de promover un uso completo de todas sus capacidades. Por fin, la formación escolar del individuo era una condición para la garantía de su bienestar y, consecuentemente, al interés público mutuo de los hombres.

PALABRAS CLAVE: Estados Unidos. John Dewey. Democracia. Educación escolar.

Artigo recebido em setembro de 2016

Aprovado em novembro de 2016 
RAZÕES HISTÓRICAS | Karine Biasotto e Maria Inalva Galter

\section{1| INTRODUÇÃO}

John Dewey (1859-1952) teve uma carreira profícua ${ }^{1}$ que durou em torno de sete décadas dedicadas à filosofia, educação, psicologia, sociologia e política. Kenneth Teitelbaum e Michael Apple (2001), contextualizando o pensamento do autor, dizem que "Tanto durante a sua vida quanto depois da sua morte, os escritos e as posições públicas de Dewey têm sido sujeitas a uma interpretação e reinterpretação por um sem número de estudiosos" (p. 195). Esses estudiosos informam sobre a existência de uma literatura vasta sobre o seu pensamento, ou escrita por ele mesmo, com ajuizamentos distintos referentes à natureza e impacto do seu trabalho.

Nessa literatura avulta o caráter ambíguo das interpretações sobre o pensamento de Dewey. Teitelbaum e Apple (2001), a esse respeito dizem que ele tem sido julgado tanto como santo quanto como pecador, respeitado pela defesa que fez da educação progressista e da democracia, mas condenado pelo seu presumível papel na "fragilização" da escolarização estadunidense e destruição das tradições. Apontam também que nessa literatura ora ele é ressaltado pela defesa que fez da sociedade industrial numa perspectiva democrática ora é denunciado por ter se limitado a uma visão que conciliação entre as classes sociais.

Mais recentemente, de acordo com Teitelbaum e Apple (2001), Dewey tem sido retomado "[...] tanto como um predecessor da crítica cultural pós-estrutural, quanto como o filósofo mais importante do pragmatismo estadunidense" (p. 195). Todavia, segundo esses autores, não obstante o lugar de destaque que ele ocupa no discurso acadêmico ao longo do século XX, "[...] as verdadeiras ideias de Dewey, [...], nunca permearam o sistema educativo estadunidense" ( $p$. 195). Concluem a esse respeito, com as palavras do próprio Dewey que pouco antes de sua morte em 1953, disse "[...] há muito mais conversa sobre a educação progressista do que propriamente a sua implementação" (DEWEY, 1953, apud Teitelbaum e Apple, 2001, p. 195).

No Brasil, a historiadora da educação Maria da Glória de Rosa (2009), comenta as distintas interpretações sobre o pensamento de Dewey, encontrando ora prosélitos ora adversários.

Visando contribuir com esse debate, nesse artigo é examinado o pensamento de John Dewey no contexto estadunidense no transcorrer das décadas finais do século XIX e primeira metade do século XX. O principal objetivo é analisar as razões históricas que fundamentam a proposta educacional do autor, particularmente no que se refere ao conceito democracia e educação escolar.

$\mathrm{Na}$ reflexão são utilizados alguns autores que tratam sobre a história dos Estados Unidos e ou sobre o pensamento de Dewey, tais como: William Miller (1962), Alonzo Hamby (2005), Carlos Otávio Fiuza Moreira (2002) e Luiz Estevam Fernandes e Marcus Vinícius de Morais (2014). Também fundamenta-se nas seguintes obras de Dewey: Meu credo pedagógico (1897), Democracia e Educação (1916) e Experiência e Educação (1938).

\footnotetext{
${ }^{1}$ Por volta de 1961, na ocasião da republicação integral da obra de Dewey pelo Center of Dewey Studies, localizado na Universidade de Southern Illinois Carbondale, especialistas dividiram a obra do autor, em três coleções: The Early Works (1882-1898), de cinco volumes; The Middle Works (1899-1924), de quinze volumes; e The Later Works (1925-1953), com dezessete volumes (ANDRADE, 2007, p. 15).
} 


\section{2 | CONTEXTO HISTÓRICO E SOCIAL DE JOHN DEWEY}

A época vivida por Dewey foi marcada por uma crescente industrialização, urbanização e avanços no campo da ciência ${ }^{2}$ e da tecnologia que acarretaram enormes transformações sociais, econômicas, políticas e culturais em âmbito mundial e, particularmente, nos Estados Unidos da América. Com vistas a atender a este novo ideal de vida, o autor, assim como muitos outros intelectuais que viveram essa realidade, percebeu como necessário formular teorias, tendo em vista refletir e propor alternativas aos problemas sociais demandados em sua época.

Segundo Miller (1962), um dos acontecimentos de grande importância, e que marcou a vida do povo americano nas décadas finais do século XIX repercutindo nas décadas iniciais do século XX, foi, sem dúvida, a Guerra Civil Americana (1861-1865). Esse conflito materializou as disputas políticas, econômicas e ideológicas entre os estados do sul (Confederados) e os estados do norte (União) e, ao seu fim, efetivou as características da economia norte-americana ${ }^{3}$.

No que diz respeito à esfera política, os fazendeiros do sul, em sua maioria, apoiavam o Partido Democrata ${ }^{4}$. Enquanto os industriais do norte apoiavam o Partido Republicano ${ }^{5}$ e prezavam pelo crescimento do setor com uso de mão de obra assalariada.

A eleição de 1860 trouxe consigo um presidente republicano, Abraham Lincoln, homem que, nas palavras de Fernandes e Morais, "era favorável aos ideais de solo livre, trabalho e homens livres." (FERNANDES; MORAIS, 2014, p. 130). Segundo os autores, a eleição de Lincoln teria insuflado mais as diferenças entre os estados do sul e norte e foi o estopim para o início do conflito. Essa diferença pesou ainda mais em 1862, quando Lincoln proclamou a liberdade dos escravos negros em todos os estados Confederados. Contudo, como apresentam Fernandes e Morais (2014), é necessário enfatizar que tanto nos estados Confederados quanto nos estados da União havia a ideia de que o homem branco era superior, fato esse, destacado até mesmo nos discursos do presidente Lincoln.

A libertação dos escravos trouxe a impressão de que esse seria um passo rumo a uma sociedade na qual cada indivíduo teria, juridicamente, garantidos os direitos de fazer suas escolhas, dando-se, assim, mais vida aos ideais liberais.

Ao fim dos conflitos da Guerra Civil Americana, o sul estava economicamente e socialmente desestruturado como mostram Fernandes e Morais (2014). Enquanto isso, o processo de industrialização do norte crescia com a própria guerra, sobretudo a indústria têxtil e bélica. De acordo com os autores, além de unificar o país, o conflito favoreceu a criação da identidade nacional estadunidense, fundamentada no modo de pensar e de produzir dos estados do norte.

Do fim da Guerra Civil até a Primeira Guerra Mundial, segundo Hamby, "os Estados Unidos da América atingiram a sua maioridade." (HAMBY, 2012, p. 170). Formou-se um país urbanizado, onde se localizavam diversas fábricas, siderúrgicas e ferrovias. Associada a prosperidade, o autor destaca os problemas que com ela vieram, como o monopólio de poucos grupos sobre a indústria, as más condições de trabalho que os operários enfrentavam e o crescimento desordenado das cidades.

\footnotetext{
${ }^{2}$ Segundo Dewey, "por ciência, [...] significamos aquele saber proveniente dos métodos de observação, reflexão e verificação deliberadamente adotados para assegurar conhecimentos certos e provados.” (DEWEY, 1979, p. 241).

${ }^{3} \mathrm{O}$ norte, mais avançado em termos industriais, tinha uma classe média nascente e uma indústria de importância crescente. O sul, embora apresentando características fundamentalmente agrícolas, baseava-se no sistema de plantation e escravidão; muito bem inserido no sistema capitalista [...] interagia economicamente com o norte e participava do comércio internacional, especialmente com a Inglaterra. (FERNANDES; MORAIS, 2014, p. 129).

${ }^{4}$ Consultar: www.democrats.org/about/our-history.

${ }^{5}$ Consultar: www.gop.com/history.
} 
O acelerado processo de industrialização, para Moreira, "não significou apenas a criação de uma grande quantidade de fábricas, mas também de intensas modificações das atividades laborais." (MOREIRA, 2002, p. 56). Fernandes e Morais mostram que "atraída pela 'terra das oportunidades', entre 1870 e 1900, a população dos Estados Unidos recebeu mais de 20 milhões de imigrantes vindos da Europa e da Ásia, em sua maioria." (FERNANDES; MORAIS, 2014, p. 153). Essa numerosa mão de obra, composta de homens, mulheres e crianças, passou a valorizar as tarefas mecânicas nas fábricas norte americanas.

Essas tarefas automáticas, junto às inovações científicas implantadas nas fábricas, configuram-se no que Moreira chama de "ciência da produção." (MOREIRA, 2002, p. 56). Essa teoria foi idealizada por Frederick Winslow Taylor $(1856-1915)^{6}$ e passou a consistir uma forma de organizar o trabalho que se torna primordial nas fábricas norte-americanas.

Como fato decorrente da prosperidade industrial, vê-se que os sindicatos começam a se fortalecer. Foi este, também, um período de reivindicações sociais por meio de greves, por exemplo, aquela ocorrida na cidade de Pullman, quando os operários pararam o trabalho devido ao rebaixamento no salário7.

A população de Chicago também sentiu os efeitos da urbanização e industrialização, ressalta Moreira (2002). Em 1890, 87\% a sua população era formada por imigrantes, como apontam Fernandes e Morais (2014). Por esse motivo, foram criadas instituições sociais para ajudar, principalmente, os imigrantes recém-chegados aos Estados Unidos e a população mais carente. Dewey foi integrante ativo em uma dessas organizações, a Hull House, onde de acordo com os registros de Moreira (2002) eram desenvolvidos projetos filantrópicos para socializar a população marginalizada.

Nesse contexto, Dewey dedicava-se à Escola Laboratório da Universidade de Chicago, quando escreveu Meu Credo Pedagógico (1897) a fim de expor seu ideal para a educação. Para o autor, a educação do indivíduo se dá nas experiências que realiza no meio físico e na vida social, sendo um processo que ocorre ao longo da vida ${ }^{8}$. Desde seu nascimento, este forma hábitos e estende suas emoções ao longo do seu desenvolvimento. De modo que "ele se converte assim, em herdeiro do capital formado pela civilização." (DEWEY, 1954, p. 75). No entender de Dewey, a educação que ele chama de verdadeira, vem do estímulo das relações sociais em que cada criança se encontra. Interpretar adequadamente essas relações sociais é essencial para compreender as capacidades das crianças.

O autor afirmava que na condição do mundo, num momento em que a democracia torna-se cada vez mais desejável e que a industrialização se desenvolve de forma intensa, tornou-se impossível imaginar como a sociedade seria em longo prazo, fato que impossibilita preparar uma criança para condições estanques. Diante dessa dificuldade no que diz respeito à educação das crianças, explica Dewey, "prepará-la para a vida ulterior significa proporcionar-lhe o domínio de si mesma; significa educá-la de sorte que tenha o pleno e rápido uso de todas as suas capacidades." (DEWEY, 1954, p. 76-77).

\footnotetext{
${ }^{6}$ Frederik Winslow Taylor (1856-1915), engenheiro norte americano que introduziu na indústria o conceito de administração científica (RAGO; MOREIRA, 2003, p. 14). Para Taylor, "o objetivo mais importante de ambos, trabalhador e administração, deve ser a formação e aperfeiçoamento do pessoal da empresa, de modo que os homens possam executar em ritmo mais rápido e com maior eficiência os tipos mais elevados de trabalho, de acordo com suas aptidões naturais. " (TAYLOR, 1986, p. 33).

${ }^{7}$ Dewey participou desse movimento grevista.

${ }^{8}$ Durkheim (2012, p. 110) também afirma a importância da educação na formação das potencialidades dos indivíduos segundo as exigências da sociedade. O autor postula que a educação é o meio fundamental pelo qual a homogeneidade social é garantida como também pela formação especializada que visa adaptar os indivíduos as demandas sociais contemporâneas.
} 
No início do século XX a relação entre ciência e indústria tornou-se mais estreita, resultando na criação de novos produtos e na expansão de capital para o exterior. Fernandes e Morais relatam que, nesse contexto, os Estados Unidos "viveram um período de euforia industrial, que louvava o próprio crescimento, capaz de 'integrar o país' e torná-lo competitivo diante das maiores nações industrializadas da Europa." (FERNANDES; MORAIS, 2014, p. 156).

Esse crescimento econômico favoreceu a ampliação do poder aquisitivo para todas as classes sociais. "Foram concedidos salários mais elevados aos operários qualificados, ensaiando-se os primeiros passos rumo ao chamado capitalismo do bem-estar social." (MILLER, 1962, p. 270). Por outro lado "As condições incrivelmente insalubres do que os operários chamavam de suas 'casas', tornavam mais penoso o custo social da estabilidade." (MILLER, 1962, p. 276).

Essa prosperidade industrial chamou a atenção de imigrantes europeus e africanos originários do sul dos Estados Unidos que viram nela uma oportunidade de melhorar as condições de existência, fazendo com que se deslocassem para os centros urbanos fabris.

Em 1914 houve a eclosão da Primeira Guerra Mundial (1914-1918) na Europa. Em 1917, os Estados Unidos entraram no conflito mundial. A visão que o presidente Wilson tinha sobre a participação dos Estados Unidos na guerra era de uma luta pela "democracia e liberdade", como mostra Fernandes e Morais (2014).

Até então os Estados Unidos somente forneciam munições e equipamentos aos países Aliados, fato que estremeceu a relação com a Alemanha ${ }^{9}$. A única forma de manter o país distante da guerra seria finalizar o conflito. "Nenhuma das partes beligerantes achava-se, porém, preparada para aceitar sua proposta de 'paz sem vitória'." (MILLER, 1962, p. 309). No entanto, Fernandes e Morais (2014) mostram que a guerra foi uma oportunidade para consolidar a supremacia econômica do país e aliviar os próprios conflitos internos.

O presidente Wilson organizou, em 1917, uma comissão encarregada de fazer a propaganda da guerra junto à população americana justificando que "ela tornaria o mundo seguro para a democracia; era uma guerra destinada a pôr termo nas guerras." (MILLER, 1962, p. 311). Na mente do norte-americanos a ideia de "patriotismo em nome da democracia e liberdade além-mar (contra a Alemanha) e em casa (contra a desigualdade econômica) dominou o discurso oficial do governo e de muitos dos movimentos." (FERNANDES; MORAIS, 2014, p. 194).

Para isso, Wilson anunciou, em janeiro de 1918, os "quatorze pontos"10 que definiam os objetivos da guerra. Dessa forma, sugeria-se um fim mais rápido para o conflito. Em outubro daquele ano, a Alemanha declarou aceitar a execução das condições de Wilson e pôr fim à guerra.

Em janeiro de 1919 teve início a Conferência de Versalhes ${ }^{11}$, que organizou as condições de paz impostas à Alemanha. Grande parte dos pontos propostos por Wilson estava incluído no Tratado de Versalhes quanto às novas fronteiras europeias e à determinação das formas democráticas

\footnotetext{
${ }^{9}$ Hobsbawm (1995) observa que, no que diz respeito à indústria norte-americana no contexto de Primeira Guerra Mundial, a economia dos Estados Unidos foi beneficiada pelo fato do país estar geograficamente distante do conflito e pela organização da sua produção.

${ }^{10}$ Dentre os pontos contavam-se as exigências de uma diplomacia franca, da liberdade dos mares, da remoção das barreiras comerciais e do ajustamento das fronteiras a base do princípio de autodeterminação dos povos interessados. No ponto quatorze, Wilson advogou pela criação de uma liga das nações - "que proporcionasse garantias mútuas de independência política e integridade territorial aos grandes e pequenos estados." (MILLER, 1962, p. 211). ${ }^{11}$ Organização do tratado de paz ao fim da Primeira Guerra Mundial que foi, por fim, assinado em 28 de junho de 1919. Pelo tratado, a Alemanha se comprometia em assumir a responsabilidade pelo conflito e a cumprir inúmeras exigências políticas, econômicas e militares impostas, principalmente, pela Inglaterra e França.

https://cpdoc.fgv.br/producao/dossies/AEraVargas1/anos20/Centenariolndependencia/ConferenciaDeParis. Acesso em: 30 mar. 2016
} 
de governo. Além disso, incluía o pagamento de reparações financeiras pelo estado alemão aos países aliados e, numa tentativa de minimizar a situação, instituiu-se a Liga das Nações ${ }^{12}$.

Num contexto em que os Estados Unidos se envolviam em questões internacionais e viviam, em seu próprio território, tensões sociais, políticas, étnicas e raciais de toda ordem, Dewey se ocupou da reforma educacional, ressaltando a importância em considerar a experiência social e individual dos homens.

Mediante os conflitos que desequilibravam a sociedade estadunidense em sua época, Dewey dedicou-se, entre outras questões, a refletir sobre a importância da experiência democrática, tendo em vista a manutenção e o desenvolvimento da sociedade. Nesse período passou a discutir com mais frequência problemas políticos de acordo com Moreira (2002).

Dewey escrevia sobre temas como sociedade, democracia e educação. Assim, é demonstrativo de que o momento que o autor vivia era de conflitos relacionados a essas temáticas. Naquele momento os Estados Unidos passavam, conforme se pode observar no fragmento destacado a seguir, por um momento de restrição ao número de imigrantes:

Em 1917, a propósito do último de um certo número de vetos de Wilson, o Congresso impôs aos que procurassem estabelecer-se nos Estados Unidos a obrigação de provar que sabiam ler e escrever. Essa prova constituiu uma barreira, conforme se revelou em 1920, quando perto de um milhão de imigrantes afluíram o país. (MILLER, 1962, p. 319).

Essa restrição, oriunda de decretos oficiais ${ }^{13}$ às minorias gerou ataques violentos a pessoas oriundas de diferentes etnias que já viviam nos Estados Unidos. A Ku Klux Klan ${ }^{14}$ se fortaleceu do favorável clima de xenofobia instaurado no país nos anos 1920: "em 1924, cerca de 4.500.000 'pessoas do sexo masculino, cidadãos nascidos nos Estados Unidos e cristãos' - haviam entrado para a agremiação encapuzada." (MILLER, 1962, p. 320). Essa organização perseguia a todos os grupos que, segundo compreendiam, não contribuíam ao "americanismo". Isso incluía, além dos afro-americanos, os judeus, os católicos e os defensores da teoria de Darwin.

Precisamente, conforme aponta Moreira (2002), a teoria de Darwin fora um importante elemento para Dewey ao elaborar sua própria teoria sobre educação, como se pode observar no comentário destacado na sequência:

O naturalista inglês afirmara que as estruturas da vida não tinham formas pré-determinadas; isto torna a experiência um fator decisivo para a evolução das espécies. Crescimento, adaptação e uso da inteligência para a resolução de questões são marcas da filosofia da educação de Dewey. (MOREIRA, 2002, p. 17).

A ciência, como temos destacado, fez-se presente na indústria a partir de meados do século XIX

\footnotetext{
${ }^{12}$ A Liga das Nações foi uma organização internacional criada em abril de 1919, quando a Conferência de Paz de Paris adotou seu pacto fundador, posteriormente inscrito em todos os tratados de paz.. https://cpdoc.fgv.br/ producao/dossies/aeravargas1/anos20/centenarioindependencia/ligadasnacoes Acesso em: 30 mar. 2016.

${ }^{13} \mathrm{O}$ ato de imigração de 1924 reduziu o número de imigrantes admitidos a 150 mil por ano, menos de $15 \%$ da média de um milhão nos anos antes da guerra; mesmo assim, oficiais da imigração raramente permitiram que metade desse número efetivamente entrasse no país. Cotas raciais e étnicas dos prospectivos imigrantes foram adotadas em proporção aos números da "estatística nacional e linguística" de 1970! Como resultado, quase todos os povos asiáticos e muitos europeus foram excluídos da entrada nos Estados Unidos no período. Novas categorias de "cidadão" e "estrangeiro" foram formuladas com base em noções racistas e a fronteira dos estados unidos começou a ser policiada pela primeira vez. (FERNANDES; MORAIS, 2014, p. 202).

${ }^{14}$ Sobre a Ku Klux Klan, consultar: CARNEIRO, 2006, p. 9.
} 
contribuindo com o período de expansão dos negócios que seguiu até 1929. Registra-se que "esse surto de negócios foi o mais longo da história americana, alimentando a acariciada crença de que os Estados Unidos haviam descoberto a máquina do moto-perpétuo da prosperidade." (MILLER, 1962, p. 326). Esse avanço da indústria ocorreu com auxílio do progresso científico, atrelado à guerra e aos lucros gerados pela mesma.

Essa prosperidade industrial acarretou em um aumento da produtividade do trabalho e em uma ascensão salarial para os operários das indústrias modernas. Dessa forma houve um aumento do poder aquisitivo da população em geral e a publicidade tornou-se um meio de criar consumidores, já que "os anunciantes passaram a desviar rapidamente seus apelos de venda aos argumentos utilitários e informações descritivas do produto para apelos emocionais por status e diferenciação social." (RIFKIN, 1995, p. 21).

Essa prosperidade durou até 1929, quando a economia norte-americana entrou em declínio, como explicam Fernandes e Morais no fragmento que segue: "As amplas esperanças da nova era faliram na 'Quinta Negra', 24 de outubro de 1929. Nesse dia, a Bolsa de Valores nos Estados Unidos caiu em um terço, dando origem à pior crise econômica na história do capitalismo mundial." (FERNANDES; MORAIS, 2014, p. 205).

Como consequência da derrocada da economia, e fundamentado no pensamento de John Maynard Keynes ${ }^{15}$, o presidente Franklin Roosevelt instituiu medidas de reforma, o New Deal ${ }^{16}$, com a finalidade de reestruturar financeiramente os Estados Unidos. Como ressaltam Fernandes e Morais "Roosevelt reconheceu que a intervenção estatal massiva era necessária para salvar o sistema econômico e aliviar o conflito social." (FERNANDES; MORAIS, 2014, p. 209).

Sobre o New Deal, de um modo geral, Fernandes e Morais (2014) destacam que alcançou resultados modestos se comparados ao estado de bem-estar social dos países europeus. Contudo, o que se alcançou de fato foi à garantia de qualidade de vida e proteção social para os cidadãos americanos.

No início da década de 1930, começou a se desenhar uma nova guerra de proporções mundiais: "Em 1935, Mussolini invadiu a Etiópia, ao passo que os Estados Unidos e os membros da Liga das Nações deixaram-se ficar impassíveis." (MILLER, 1962, p. 343). A posição norte-americana era a de manter a neutralidade, que teve como maior medida, sancionada em 1937, a de proibir o empréstimo de dinheiro e venda de munições a países em guerra.

Com a efetivação da Segunda Guerra Mundial foram reformuladas as leis norte-americanas de neutralidade. Assim, foi permitida aos beligerantes a compra de munições, desde que à vista e transportadas em navios próprios.

Quando Hitler quebrou o acordo de não agressão que havia feito com Stalin, os ingleses uniram-se aos russos na guerra e começaram a realizar reuniões junto aos Estados Unidos, na condição de não beligerante, com objetivo de apressar o fim da guerra. Roosevelt participou da Conferência de Argentia ${ }^{17}$. Nessa ocasião foram reiterados muitos dos Quatorze pontos de Wilson, organizados ainda na Primeira Guerra Mundial e um acordo de estreitamento de relações entre britânicos e americanos.

\footnotetext{
${ }^{15}$ John Maynard Keynes (1883-1946), economista inglês que elaborou o modelo de Welfare State. (MEDEIROS, 2013, p. 44).

${ }^{16} \mathrm{O}$ New Deal introduziu reformas sociais e econômicas nos Estados Unidos, tendo representado o culminar de uma tendência de longo alcance para o abandono do capitalismo "laissez faire". (HAMBY, 2012, p. 238).

${ }^{16}$ Reunião realizada no Canadá por iniciativa de Winston Churchill e Franklin Roosevelt. Os líderes discutiram seus objetivos de guerra que foram sistematizados em um documento conhecido como "Carta do Atlântico".

Disponível em: <http://www.exordio.com/1939-1945/codex/conferencias/terranova.html> acesso em: 25 ago. 2015
} 
Mais uma vez o país de Dewey via-se às voltas com questões que extrapolavam seus limites territoriais por conta de conflitos entre as diversas nações, preocupação que permeava o pensamento do autor.

No contexto que antecede a Segunda Guerra, Dewey elaborou Experiência e Educação (1938), de acordo com Andrade (2007), como uma resposta a incompreensão de suas ideias sobre educação, com a clareza de que sua obra traz renovação às práticas educativas, não no sentido de romper com o passado, mas para responder a antigas inquietações da filosofia da educação.

$\mathrm{Na}$ tentativa de pontuar explicações a respeito da teoria de Dewey, Alfred L. Hall-Quest relata, na apresentação de Experiência e Educação, que

[...] surgindo em meio à generalizada confusão, que lamentavelmente dispersou as forças da educação nos Estados Unidos e exaltou lemas de escolas e fés em conflito, este pequeno volume oferece roteiro claro e seguro para uma frente comum em educação. (DEWEY, 1976, p. XI).

$\mathrm{Na}$ apresentação dessa obra feita por Hall-Quest relata-se também o momento histórico de Experiência e Educação. Havia a cisão em duas diferentes partes ${ }^{18}$ na educação norte-americana. Isso significava que essas diferentes formas de existência "a enfraquecem num momento em que toda a sua força é necessária para guiar a nação perplexa por entre os reverses da mudança social." (DEWEY, 1976, XI). Sobre esse enfraquecimento, Dewey ressalta, ao escrever o prefácio da obra, que

[...] nesse contexto é que sugiro, ao fim desde pequeno volume, que todos os que olham para frente em busca de um novo movimento em educação, adaptando a necessidade presente de uma nova ordem social, pensem em termos de educação e não de qualquer 'ismo', mesmo que seja progressivismo. (DEWEY, 1976, XI).

O autor mostra, assim, a necessidade de adequar a educação à sociedade que estava em processo de transformação, tendo como ideal garantir a participação de todos os indivíduos com as suas diferenças, dar a eles direção social e, assim, harmonizar as relações sociais, tornando-as democráticas a partir da escola enquanto um esboço dessa vida social.

\section{3 | A EXPERIÊNCIA EDUCATIVA COMO LÓCUS DA DEMOCRACIA}

Diante da complexa e contraditória vida social das décadas finais do século XIX e iniciais do século XX, Dewey se posicionou como um defensor do ideal democrático de sociedade. A construção da sociedade democrática é uma questão fundamental na proposta pedagógica do autor, sendo, portanto, elemento primacial da sua compreensão de experiência educativa.

Dewey sistematizou o seu conceito de democracia na obra Democracia e Educação (1916). Para formulá-lo, baseia-se na ideia de que a sociedade está em constante processo de mudança. Sendo assim, a educação, que a seu ver, tem como função social "assegurar a direção e o desenvolvimento dos imaturos, por meio de sua participação na comunidade a que pertencem" (DEWEY, 1979, p. 87) deve não somente adaptar os indivíduos a essa mudança, mas, também, ser um meio de estímulos à própria mudança.

${ }^{18} \mathrm{O}$ autor não explica essa cisão. 
Para defender essas ideias, o autor, inicialmente, afirma que cada sociedade considerada historicamente produz o seu próprio espírito e o seu próprio método de educação. Mas, para Dewey, a discussão sobre o que seja pensamento, educação e sociedade não constitui algo fácil, linear e trivial. Ao contrário, trata-se de algo contraditório, que envolve interesses distintos e diz respeito mesmo ao todo social.

Tal aspecto pode ser constatado quando o autor trata sobre o significado do que seja associação humana, isto é, o que seja a sociedade, "uma só palavra, mas significa muitas coisas". (DEWEY, 1979, p. 87). De acordo com seu raciocínio,

\begin{abstract}
[...] um homem se acha incluído em uma multidão de grupos diferentes, nos quais os seus consócios podem ser completamente distintos. Figura-se, com frequência, nada terem estes grupos de comum, exceto o serem modos de vida associada. Dentro de toda larga organização social existem numerosos grupos menores: não somente subdivisões políticas, senão também associações industriais, científicas e religiosas. Existem partidos políticos com diferentes aspirações, seitas sociais, quadrilhas, conventículos, corporações, sociedades comerciais e civis, grupos estreitamente ligados pelos vínculos do sangue, e outros mais, em infinita variedade. Em muitos casos países modernos e em alguns antigos, há grande diversidade de nacionalidades, com diferentes línguas, religiões, códigos morais e tradições. Sob este ponto de vista, [...] são mais um agregado de sociedades frouxamente unidas do que uma compreensiva e bem amalgamada comunidade de ação e de pensamento. (DEWEY, 1979, p. 87-88).
\end{abstract}

Sociedade e ou comunidade ${ }^{19}$ são termos complexos que encerram até mesmo ambiguidades. Por essa razão, o autor atribui-lhes dois sentidos: um normativo e outro descritivo; "uma significação de jure e outra significação de fato." (DEWEY, 1979, p. 88). Em filosofia social, assevera que predomina a primeira acepção, afirmando a "sociedade como uma pela sua própria natureza" (DEWEY, 1979, p. 88, destaque do autor), cujas "qualidades que acompanham essa unidade, a louvável comunhão de bons propósitos e bem-estar, de fidelidade aos interesses públicos e reciprocidade de simpatia, são postas em relevo e encarecidas." (DEWEY, 1979, p. 88).

Contudo, a unidade social, algo primacial para o florescimento da vida individual e coletiva não se forma sem um pensamento deliberado. Considerando a existência das mais diversas e distintas associações humanas cada qual defendendo o seu próprio interesse como estabelecer critérios que permitam pensar a vida dos indivíduos em sociedade? Dewey sintetiza o seu método de análise ao explicar que é necessário "[...] extrair os traços desejáveis das formas de vida social existentes e empregá-los para criticar os traços indesejáveis e sugerir melhorias". (DEWEY, 1979, p. 89).

Somente baseado em critérios que levem em conta àqueles elementos que indiquem unidade $e$ àqueles que revelem certa interação e reciprocidades entre as diversas e diferentes associações é que se pode dar certa exiguidade a um dado ideal social.

Evidentemente que nem todos os hábitos e valores de um grupo particular interessam ao conjunto da sociedade, pois, se a educação ministrada em um dado grupo social tende a socializar seus membros, a qualidade e o valor da socialização dependem dos hábitos e aspirações do grupo. Contudo, há muitos interesses que são comunicados e compartilhados, "existem vários e livres pontos de contato com outras modalidades de associação" (DEWEY, 1979, p. 89) e que são mesmo imprescindíveis para a melhoria da vida em sociedade.

Tendo em vista discutir a sua concepção de sociedade democrática, o autor partindo de elementos de unidade e de diversidade entre as distintas associações menciona um exemplo de país

${ }^{19}$ Ao descrever os dois termos, o autor não os diferencia. 
cujas relações entre governantes e governados sejam permeadas por práticas despóticas. Cabe observar, também, que o sentido de governo despótico mencionado pelo autor é amplo, referindo-se às relações existentes nas instituições e nas práticas sociais não se restringindo, apenas, ao Estado político.

Primeiramente o autor postula que não se constitui em uma verdade o fato de que não existam, num país cujas relações se dão pelo despotismo, alguns interesses que sejam comuns entre governantes e governados. Afinal, de alguma maneira, a "autoridade deve apelar [...] à atividade inata dos súditos e por em jogo algumas de suas aptidões." (DEWEY, 1979, p. 90). Para reforçar essa ideia, baseia-se nas observações de Talleyrand a respeito da questão: "um governo podia tudo fazer com baionetas, menos assentar-se sobre elas". (DEWEY, 1979, p. 90). Conclui, então, que, numa sociedade despótica, o vínculo social não se faz unicamente pelo uso da força coercitiva, mas, também, pelo temor e pela esperança, que são capacidades mobilizadas nos indivíduos que - para conseguirem alguma recompensa, certo conforto e bem-estar - sujeitam-se ao governante.

No que se refere ao temor, o autor ressalta que ele tem certa importância na vida do indivíduo. Afinal, em certas circunstâncias o instinto do medo é mesmo desejável sendo manifestado em qualidades como a cautela, a circunspecção, a prudência, o desejo de prever futuros acontecimentos para evitar o que é prejudicial ao indivíduo. Por outro lado, ele pode mobilizar a covardia e a subserviência, que são traços de comportamento que geram ações condenáveis.

É nesse aspecto que ele critica o governo despótico que, a seu ver - ao apelar unicamente para as ações coercitivas no comando -, dispõem o indivíduo a desenvolver atributos que o levam a buscar apenas satisfazer interesses particulares, o que cria uma barreira que dificulta o próprio desenvolvimento e, por conseguinte o desenvolvimento da própria sociedade.

Numa sociedade com esse modelo de governo o interesse comum é limitado e não há livre reciprocidade entre os indivíduos e os grupos e classes sociais. As classes sociais se distanciam, impedindo, assim, "a endosmose social". (DEWEY, 1979, p. 90). A falta do livre intercâmbio, que favoreceria o contato entre os vários interesses compartidos, provoca um grande desequilíbrio na sociedade, atingido as diferentes classes sociais.

O autor postula que quando as divisões de classes se polarizam obstaculizando a mútua comunicação das experiências que ficam cada vez mais restritas a poucas linhas definidas. Neste caso, as experiências tendem, por um lado, a se converter em rotina para a classe de condições menos favorecidas e, por outro lado, a favorecerem ações caprichosas, impulsivas e sem objetivos para a classe em boas condições materiais.

Defendendo a importância de que na sociedade o que deve prevalecer é o interesse público e também aqueles interesses que, sendo particulares, possam ser compartilhados por todas as classes, o autor critica a classe mais abastada que, a seu ver, ao primar pelo seu próprio interesse, age no governo dos homens de forma unilateral, obstaculizando o progresso do indivíduo e da própria sociedade.

Nesse sentido, a cooperação é um elemento essencial ao entender de Dewey, pois a seu ver a diversidade de experiências trazidas por cada indivíduo pode contribuir para construção social quando compartilhadas. O autor critica a visão unilateral que privilegia um interesse particular de outrem em detrimento da cooperação entre os indivíduos e as classes sociais. Para ele, toda a dificuldade e a limitação das ações humanas vividas na sociedade de sua época decorriam do não compartilhamento de interesses sejam em nível individual e ou entre os grupos e ou classes sociais. Essa dificuldade e limitação se manifestam, segundo o autor, quando o indivíduo não compreende e nem apresenta nenhum interesse pessoal na atividade a que se dedica. 
RAZÕES HISTÓRICAS | Karine Biasotto e Maria Inalva Galter

A esse respeito, Dewey, retoma o significado de escravo ${ }^{20}$ utilizado por Platão, afirmando que, quando o indivíduo age em quaisquer situações de vida sem um interesse próprio, mas conduzido por interesses alheios ao seu próprio interesse, ele assemelha-se a um escravo, uma vez que,

[...] o escravo, [...], é o homem que recebe de outro os objetivos que orientam sua conduta. Manifesta-se esta condição mesmo quando não haja escravidão no sentido legal desta palavra. Ela existe sempre que um homem se dedica a uma atividade, cuja utilidade social ele não compreenda e que não encerre para ele algum interesse pessoal. (DEWEY, 1979, p. 91).

Essa compreensão de que o indivíduo torna-se um escravo ao realizar qualquer atividade cujo interesse esteja apenas vinculado ao interesse particular de um outro, não atendendo de alguma maneira o seu próprio interesse e/ou o interesse geral, é a base da teoria pedagógica de Dewey. O contrário de agir como um escravo das vontades alheias, ao entender de Dewey, é agir com objetivos, é agir inteligentemente ${ }^{21}$.

As ideias acerca do interesse pessoal e da utilidade social são muito caras para Dewey e perpassam toda a reflexão que ele realiza a respeito do seu ideal de democracia e educação. É o que podemos ver quando ele trata, por exemplo, da organização científica do trabalho, uma questão primordial de sua época e que busca responder às demandas sociais que caracterizam as relações entre capital e trabalho nas décadas iniciais do século XX.

Ao analisar as proposições dominantes acerca da organização científica do trabalho, o autor critica o fato de elas estarem centradas apenas nos aspectos técnicos de controle que visam assegurar a eficiência dos movimentos do trabalhador na produção e na comercialização dos produtos e não se atentarem para a importância de que ele compreenda e tenha interesse pelo processo que envolve a sua atividade. Esse modelo unilateral, predominante entre os homens da indústria, na perspectiva do autor, ainda que possa gerar maior eficiência no processo de trabalho e resultar em maiores lucros para as empresas, é muita danosa para o trabalhador e, por conseguinte, para a própria sociedade na medida em que gera maior desequilíbrio nas relações. Vejamos, no fragmento a seguir, como Dewey reflete sobre esse assunto:

\begin{abstract}
Muito se tem falado sobre a organização científica do trabalho. Mas, uma visão acanhada restringe o campo da ciência a assegurar a eficiência da atuação por meio de acertados movimentos musculares ou físicos. A principal oportunidade para a eficácia da ciência será a descoberta das relações com os demais que nele tomam parte - para que o trabalhador ponha o seu interesse inteligente naquilo que estiver fazendo. A eficiência da produção exige com frequência a divisão do trabalho. Mas este se reduzirá a uma rotina maquinal se o trabalhador não vir [sic] às relações técnicas, intelectuais e sociais encerradas naquilo que estiver fazendo, em relação às demais partes do trabalho, e não se dedicar a seu trabalho por essa compreensão. (DEWEY, 1979, p. 91-92).
\end{abstract}

Dewey argumentava que o modelo científico do trabalho predominante nas indústrias, ao pautar-se apenas nos aspectos técnicos, sem dúvida produzia grande desenvolvimento. Contudo, tal

\footnotetext{
${ }^{20}$ Sobre agir sem o conhecimento do próprio trabalho, Marx assevera que no capitalismo "o trabalhador se relaciona com o produto do seu trabalho como um objeto estranho. Com base neste pressuposto, é claro que quanto mais o trabalhador se esgota a si mesmo, mais poderoso se torna o mundo dos objetos, que ele cria diante de si, mais pobre ele fica na sua vida interior, menos pertence a si próprio" (MARX, 2003, p. 112, destaques do autor).

${ }^{21}[. .$.$] esse refazer o velho por meio de sua união com o novo é precisamente o processo inteligente, é justamente$ o que chamamos de inteligência. Consiste em converter a experiência passada em conhecimento e projetar esse conhecimento em ideias e propósitos [...]. (DEWEY, 1970, p. 55).
} 
modelo não contribuía para promover os interesses sociais uma vez que não levava em conta o interesse do trabalhador, criando obstáculos ao desenvolvimento individual e ao mesmo tempo dificultando à colaboração espiritual entre as classes.

Esse pensamento do intelectual no que diz respeito às limitações impostas, sobretudo, aos trabalhadores da indústria pela diminuição do seu trabalho à execução de simples movimentos sem que haja maior contribuição desses homens pode ser articulado à sua teoria pedagógica, já que o aluno, a seu ver, também não pode executar tarefas que não tragam uma contribuição ao processo de aprendizagem. Cada indivíduo, seja um trabalhador ou um estudante, carrega em si aptidões que se desenvolvidas por meio de experiências educativas significativas edificadas pelo esforço voluntário inteligente colabora com novas e significativas experiências favorecendo o seu próprio desenvolvimento e o da sociedade.

Para Dewey, a inexistência da reciprocidade de interesses entre as classes sociais, acaba por colocar no isolamento o grupo que tem o comando de qualquer empreendimento social, dado que realça o seu espírito antissocial. Essa forma de pensamento, segundo o autor, encontra-se em qualquer grupo que privilegie seus "interesses próprios" e privam a interação com outros grupos, "de modo que o objetivo predominante seja a defesa daquilo que já conseguiu, em vez de ser sua reorganização e progresso por meio das relações cada vez de maior latitude." (DEWEY, 1979, p. 92).

Dewey, na verdade, faz críticas aos que tentam manter as instituições, as práticas e as teorias confinadas a padrões não mais condizentes com a vida social em processo de mudança. A seu ver, à medida que as diferenças entre as classes sociais se tornavam cada vez mais polarizadas, a tendência devia ser a de gerarem-se conflitos que não interessavam nem aos indivíduos e nem a sociedade em geral.

Para o autor, na esfera das relações sociais, era mesmo imprescindível levar em consideração os contatos e experiências que podiam ser compartidas entre as distintas associações. A intensa vida mental favorecida pelo intercâmbio entre os diferentes grupos sociais seria algo benéfico para a sociedade em geral, o que poderia contribuir inclusive para administrar os conflitos.

Dewey viveu num período complexo e de intensa transformação na sociedade. As relações sociais - antes pautadas na visão do grande capitão da indústria que, ao construir sua fortuna, acreditava estar contribuindo com o progresso da sociedade - estavam sendo questionados em razão das novas relações de concorrência entre as distintas nações. Essas mudanças que interferiram e redefiniram as relações entre as nações também passaram a reconfigurar as relações entre as classes sociais. A unidade necessária para a manutenção da sociedade não era mais possível apenas pelo mando de uma classe sobre a outra. Para Dewey, o intercâmbio entre as classes sociais, naquilo que é necessário para favorecer a coesão social e ao mesmo tempo o progresso do indivíduo e da sociedade, passou a ser considerado como elemento fundamental.

$\mathrm{O}$ autor atenta-se a esse fato de que na antiguidade os grupos diversos eram geograficamente distantes, e, portanto, havia uma homogeneidade entre esses grupos. Mas, também, chama a atenção para o seu país de origem, os Estados Unidos, que possuíam uma característica diferenciada pelo "incremento do comércio, dos meios de transporte, intercomunicação e da emigração, países como os Estados Unidos são compostos de uma combinação de diferentes grupos com diferentes costumes tradicionais." (DEWEY, 1979, p. 23). Dewey entende que por essa situação, talvez, tenha havido necessidade de criar instituições educacionais com o fim de equilibrar as relações pessoais desses diferentes grupos dentro de uma unidade política maior.

Podemos dizer que seu método de análise da sociedade, pautado nos critérios da unidade e da diversidade social, visa caracterizar e orientar o seu ideal da vida democrática. No que se refere à unidade ela significa "não só mais numerosos e variados pontos de participação do interesse comum, como também maior confiança no reconhecimento de serem, os interesses recíprocos, 
fatores da regulação e direção social." (DEWEY, 1979, p. 93). Quanto à diversidade, segundo ele expressa, ela [...] significa uma cooperação mais livre entre os grupos sociais [...] como também a mudança dos hábitos sociais - sua contínua readaptação para ajustar-se às novas situações criadas pelos vários intercâmbios. (DEWEY, 1979, p. 93).

A educação deliberada e sistemática tem papel fundamental na realização do ideal democrático de sociedade pleiteado por Dewey. Contudo, o autor alerta para a seguinte questão: "O amor da democracia pela educação é um fato cediço." (DEWEY, 1979, p. 93). Ao explicar a questão, o autor afirma que o governo democrático é fundado no sufrágio popular e a sua eficiência decorre da educação de seus súditos. Mas não se trata de qualquer educação uma vez que a sociedade democrática contraria qualquer princípio meramente baseado na autoridade externa. Trata-se de uma educação que desenvolva no indivíduo a capacidade de aceitação e do interesse voluntário. Mas a questão da democracia é complexa e exige uma compreensão mais profunda uma vez que ela não se encerra numa forma de governo, sendo, segundo o autor, "primacialmente, uma forma de vida associada, de experiência conjunta e mutuamente comunicada." (DEWEY, 1979, p. 93).

Essa perspectiva de democracia implica, segundo o autor, na supressão das barreiras de classe, raça e território nacional que são tidos como obstáculos que impedem o indivíduo de perceber o significado e importância de suas ações na sociedade.

A democracia, segundo Dewey, tem como características a ampliação da área dos interesses compartilhados e a libertação de maior diversidade de capacidades pessoais. Mas a seu ver essas características não foram resultados naturais de deliberação e do esforço pessoal dos indivíduos. Antes elas decorreram do desenvolvimento do trabalho da indústria e do comércio, as viagens, as migrações e intercomunicações que resultaram do domínio da ciência sobre as energias naturais, ou tiveram essas como sua causa. Contudo, essas novas condições fizeram surgir, a seu ver, maiores possibilidades de formação individual e maior comunhão de interesse, sendo que "será obra do esforço voluntário o [sic] conservá-las e aumentá-las." (DEWEY, 1979, p. 94).

Na perspectiva de Dewey, a conservação e o acréscimo de riqueza na sociedade seria obra do esforço voluntário de todos os indivíduos, cujas aptidões seriam desenvolvidas pelas experiências educativas significativas, dando ênfase em especial a educação escolar.

\section{4 | CONSIDERAÇÕES FINAIS}

Este artigo destacou que existem opiniões divergentes sobre a obra de Dewey. O intento esteve em examinar o pensamento do autor em meio ao seu contexto, e assim entender quais eram os seus questionamentos.

Por isso, no primeiro item tratou sinteticamente de alguns elementos que contribuíram para a formação e concretização dos Estados Unidos como uma nação urbana e industrializada. Foi evidenciada a Guerra Civil Americana, a expansão da indústria que colaborou para o desenvolvimento da ciência de produção, a prosperidade que levou a ocorrência da imigração europeia, as duas Guerras Mundiais e o New Deal como motor da indústria e enquanto oportunidade de ascensão política e econômica para os Estados Unidos.

Já no segundo item foi realizada uma abordagem sobre como Dewey se posiciona com relação à experiência educativa e sua relação com a própria democracia. Transparece nas palavras do autor, a ideia de que cada indivíduo, na sua particularidade pode contribuir socialmente. Mas para isso suas ações não podem ser conduzidas pela vontade alheia, e sim agindo inteligentemente. A partir dessa unidade que contribui para a diversidade os indivíduos ganham direção social. Essa forma de agir, seria desenvolvida especialmente a partir da escola. 
RAZÕES HISTÓRICAS | Karine Biasotto e Maria Inalva Galter

A partir dessas reflexões, considera-se que o pensamento de Dewey no que se refere à democracia e a educação escolar, seu significado e importância só pode ser compreendido se analisado no contexto histórico e social que lhe deu origem. Afinal, as formulações do autor, com as de quaisquer outros autores, são respostas às demandas de sua época. A importância do estudo histórico deste autor, como a de qualquer outro, está justamente na compreensão desta relação que ao revelar as demandas pretéritas, tem o potencial de contribuir com as nossas reflexões sobre os problemas contemporâneos. 
RAZÕES HISTÓRICAS | Karine Biasotto e Maria Inalva Galter

\section{Referências}

ANDRADE, Julia Pinheiro. Educação e democracia: um ensaio sobre o conceito de experiência em John Dewey. Educ. e Filos. Uberlândia, v. 21, n. 41, p. 15 - 42, jan./ jun. 2007

CARNEIRO, Maria Luiza Tucci. A tolerância como virtude. Revista USP, São Paulo, n.69, p. 6-13, março/maio 2006.

DEWEY, John. Democracia e Educação. São Paulo: Companhia Editora Nacional, 1979.

DEWEY, John. Experiência e Educação. São Paulo: Editora Nacional, 1976

DEWEY, John. Liberalismo, Liberdade e Cultura. São Paulo: Companhia Editora Nacional e Editora da Universidade de São Paulo, 1970.

DEWEY, John. Meu Credo Pedagógico. In: Pedagogia: Teoria e Prática. São Paulo: Companhia Editora Nacional, 1954.

DURKHEIM, Emile. Educação e sociologia. 3.ed. Petrópolis: Vozes, 2012.

FERNANDES, Luiz Estevam; MORAIS, Marcus Vinícius de. Os EUA no Século XIX. In: História dos Estados Unidos: das origens ao século XXI. São Paulo: Contexto, 2014.

HAMBY, Alonzo. Um Esboço da História Americana. [s.l.]: [s.n.], 2012.
HOBSBAWM, Eric. Era dos Extremos: o breve século XX: 1914 - 1991. São Paulo: Companhia das Letras, 1995.

MARX, Karl. Manuscrito Econômico-Filosóficos. São Paulo: Martin Claret, 2003.

MEDEIROS, Verenice Mioranza de. O liberalismo e as proposições de John Dewey para a educação elementar. 131f. Dissertação (Mestrado em Educação). Universidade Estadual do Oeste do Paraná, Cascavel-PR, 2013.

MILLER, William. Nova História dos Estados Unidos. Itatiaia: Belo Horizonte, 1962.

MOREIRA, Carlos Otávio Fiúza. Entre o indivíduo e a sociedade: estudo da filosofia da educação de John Dewey. Bragança Paulista: EDUSF, 2002.

RAGO, Luzia Margareth; MOREIRA, Eduardo. O que é Taylorismo. São Paulo: Brasiliense, 2003.

RIFKIN, Jeremy. O Fim dos Empregos. São Paulo: Makron Books, 1995.

ROSA, Maria da Glória. História da Educação através dos textos. São Paulo, Cultrix, 2009.

TEITELBAUM, Kenneth; APPLE, Michael. John Dewey. In: Currículo sem Fronteiras, v.1, n.2, pp. 194 - 201, Jul/ Dez 2001.

TAYLOR, Frederick Winslow. Princípios de Administração Científica. São Paulo: Atlas, 1986. 